\title{
The Technology for Preparation of Generic (Monoenantiomeric) Antimalarial Drug Primaquine by Using Supercritical Fluid Chromatography. Separation of Primaquine from Quinocide: Simultaneous Resolution of the Enantiomers of Primaquine and Their Separation from Quinocide in One Run
}

\author{
Ilia Brondz ${ }^{1,2 *}$, Anton Brondz ${ }^{3}$ \\ ${ }^{1}$ Department of Biology, University of Oslo, Oslo, Norway \\ ${ }^{2} \mathrm{R} \&$ D Department, Jupiter Ltd., Ski, Norway \\ ${ }^{3}$ Department of Chemistry, Norwegian University of Science and Technology, Trondheim, Norway \\ Email: ${ }^{*}$ ilia.brondz@bio.uio.no, ${ }^{*}$ ilia.brondz@gmail.com, brondz@stud.ntnu.no
}

Received September 16, 2012; revised October 22, 2012; accepted October 30, 2012

\begin{abstract}
Malaria is one of the most harmful diseases on the globe. According to the World Health Organization (WHO), several million people die every year from malaria, and most of them are children. Hundreds of millions of fresh cases of malaria are registered by the WHO every year, and more than one-third of the earth's population lives in malaria-endemic areas. Primaquine is an important antimalarial drug because it has gametocytocidal properties and prevents relapse in most cases. However, primaquine is a highly toxic substance, especially to the Negroid race (in Africa, Australia and North, Latin and South America) and some others. Negroid male children are most vulnerable to the toxic effects of primaquine. The toxicity of primaquine can be enhanced in mixtures with other antimalarial drugs. In the present study, unprocessed primaquine and primaquine tablets highly contaminated with quinocide (I. Brondz, Historical Overview of Chromatography and Related Techniques in Analysis of Antimalarial Drug Primaquine (Editor I. Brondz), Nova Science Publishers, Inc. (2011) ISSN 978-1-61761-944-1) are discussed versus monoenantiomeric primaquine as a drug. The contamination of primaquine with quinocide enhances the toxicity of primaquine by additive or synergistic action. The use of contaminated primaquine can be harmful. Development of a useful antimalarial vaccine can take a decade or longer. This paper describes the possibility of preparing antimalarial generic monoenantiomeric primaquine, free of both quinocide contamination and the ineffective enantiomer of primaquine, using fractionation by supercritical fluid chromatography equipped with a new experimental High Resolution Isomer Column (HRIC). By this approach, it is possible to produce a significant amount of pharmacologically active enantiomer of primaquine at relatively low cost for a broad range of patients sensitive to contaminated primaquine. Leading pharmacopoeias should no longer deny the presence of the toxic contaminant quinocide in relatively high concentrations in unprocessed primaquine and in primaquine tablets. New standards for antimalarial primaquine diphosphate tablets must be adopted in pharmacopoeias and by the pharmaceutical industry.
\end{abstract}

Keywords: Primaquine; Quinocide; High Resolution Isomer Column; Monoenantiomeric Primaquine; Malaria; SFC; New Technology Column HRIC

\section{Introduction}

\subsection{The Background to the Problem}

Primaquine is a useful antimalarial drug with gametocytocidal activity that is in use to prevent relapse [1]. Pre-

"Corresponding author. viously, at the 3rd International Symposium on Separation in BioSciences (SBS 2003), "100 Years of Chromatography" [2], evidence had been presented about the contamination of raw primaquine used in industry with the toxic substance quinocide, in percentages higher than were allowed in the British Pharmacopoeia (BP) [3-7], European Pharmacopoeia (EP) $[8,9]$ and United States 
Pharmacopoeia (USP) at the time of the presentation. Since then, unequivocal evidence has been presented by the research team of Brondz [10-23]. Some of these papers were published in well-known journals, such as the Journal of Chromatography B [10], Asian Journal of Chemistry [12], Journal of Pharmaceutical and Biomedical Analysis [16] and Journal of Chromatography A [18]. The findings were supported independently by another team of scientists [24]. Studies [10-23] used High Performance Liquid Chromatography (HPLC), HPLC-MS, GC, GC-MS and GC-MS with SMB, SFC and SFC-MS, but in [24], the contaminant quinocide in primaquine was measured by capillary electrophoresis. It is very surprising that all leading pharmacopeias are silent about the contamination of primaquine with quinocide, and about the presence of the less potent, or "silent", isomer of primaquine, which can constitute up to half the total primaquine dosage. Primaquine is a toxic drug, and the silent isomer is more toxic than the potent isomer.

\subsection{The Toxicity of Primaquine}

Primaquine is a toxic substance; its curative dose is not far from the toxic dose. Primaquine belongs to the 8aminoquinoline family of substances. The 8-aminoquinolines and primaquine exhibit several toxic effects [2538]. The main concern about the use of 8-aminoquinolines is the sensitivity of erythrocytes to primaquine alone and in combination with other antimalarial drugs. Some ethnic groups, such as Sardinians, Sephardic Jews, Greeks, Iranians and general Negroid races demonstrate a hemolytic reaction even to a normal dosage of the drug [39].

In people with a deficit of the enzyme diaphorase I (NADH methemoglobin reductase), the administration of a normal dose or even half the normal dose can be life threatening. A deficiency in cofactor NADPH results in methemoglobinemia [40].

It was demonstrated that an increased level of contamination of primaquine with quinocide increases the toxicity in an in vitro model [10]. Quinocide exhibits additive and synergistic toxicity with other antimalarial drugs [41].

\subsection{Antimalarial and Toxic Effects of Primaquine}

In contrast to the first natural antimalarial drug, quinine, primaquine is not antipyretic, analgesic or musculotropic. Primaquine exhibits strong gametocytocidal activity against all four species of Plasmodium that infect humans. It is especially active against the gametocytes of $P$. falciparum. Much attention has been directed toward primaquine since it was recognized that chloroquine does not prevent relapses in patients infected with certain strains of $P$. vivax. 8-Aminoquinolines, especially primaquine, have become the most valuable drugs in terms of potency against exoerythrocytic forms of $P$. vivax and $P$. falciparum. The drug is effective against the asexual blood forms of $P$. vivax. The ability of primaquine to serve as a killer drug for Plasmodium hypnozoites and gametocytes is still under discussion. Primaquine affects the ubiquinone function in the respiratory chain [10,42] and impairs the metabolism of the parasites' mitochondria. The ability of primaquine and quinocide to interfere with the electron transport system (in vitro model) has been taken as a criterion for the substances' toxicity [10]. It is well documented that some drugs strongly potentiate the toxic effects of primaquine for hemolysis and suppression of myeloid elements of the bone marrow. The concomitant use of quinacrine with primaquine is contraindicated. The mixture of $6.0 \%$ quinocide with primaquine is twice as toxic as the mixture of $0.5 \%$ quinocide with primaquine [10].

\subsection{The Difference between Antimalarial and Toxic Activities of Isomers and Enantiomers of Primaquine}

Olenick and Hahn [43] and later Baker et al. [44] described the main metabolites in primaquine. The studies of Baker et al. are very important in understanding the toxic effects of a mixture of primaquine with quinocide, because they studied the effects of aliphatic sidechain substituents on the antimalarial activity and on the metabolism of primaquine. Quinocide is an isomer of primaquine with a difference in the aliphatic side-chain. Quinocide is a constitutional isomer of primaquine. Primaquine is methyl-substituted at position 1' in the aliphatic side-chain, whereas quinocide is methyl-substituted at position 4' in the aliphatic side-chain. This difference in the aliphatic side-chain contributes to the significant metabolic activity of one of the isomers. In general, the placement of the methyl group at either position 1' or position 4' slows the rate of metabolism only two- to three-fold, whereas the rate of attack adjacent to the more basic nitrogen is one to two orders of magnitude higher, regardless of the placement of the methyl group [44]. This fact can explain the higher toxicity of quinocide relative to primaquine [10].

Primaquine itself consists of two enantiomers, but it is not racemic. Pharmacopeias give no information about the percentage of the $(-)$-enantiomer and the $(+)$-enantiomer present in the drug primaquine diphosphate. However, the $(+)$-enantiomer is significantly more toxic than the $(-)$-enantiomer. In the rodent model described in [45, $46]$, the $(+)$-enantiomer was more toxic than the (-)-enantiomer. The (-)-enantiomer of primaquine is transformed preferentially by mitochondrial enzymes though $\alpha$-oxidation to (-)-carboxyprimaquine, which has a relatively low toxicity [47]. The faster transformation of the 
(-)-enantiomer of primaquine to (-)-carboxyprimaquine than the (+)-enantiomer of primaquine can be a possible explanation for the lesser toxic effect of the (-)-enantiomer of primaquine in the study [45]. However, the (+)enantiomer of primaquine was found to be 6.7 -fold more potent than the (-)-enantiomer of primaquine against the non-human-infecting $P$. yodel parasite [48].

The production of primaquine with less than $0.4 \%$ quinocide contamination is needed. The existing level of contamination allowed by pharmacopoeias is not acceptable and is indefensible. The only reason for holding the permissible level of contamination as high as $1.5 \%$ is to allow the pharmaceutical industry to gain unreasonable profits [23].

The differences between the toxicity and antiplasmodium activity of the (-)-enantiomer of primaquine versus the $(+)$-enantiomer of primaquine are obvious and cannot be overlooked. The methodology for the production of monoenantiomeric primaquine (a more pharmacologically active and less toxic enantiomer) with minimal contamination with quinocide would be preferable for primaquine-sensitive patients because of the reduction in the required dose. An attempt to prepare monoenantiomeric primaquine has been claimed in a patent by Walker L., Tekwani B. and Tripathi M. (Patent Application Pub. No. US 2007/0190188 A1 of August 16, 2007). In this patent, the process previously described by Schmidt et al. [45] in 1977 and Carroll et al. [49] in 1978 was noted. Because the process was described and published more than thirty years earlier, the patent should not be accepted as original and as a first-hand claim; more details are given in [23]. However, the most pronounced shortcoming of this technology is the contamination of the enantiomer with quinocide and the inability of this process to produce the uncontaminated substance; more details of this are given in [23], pp. 177-179. The production of monoenantiomeric primaquine free of the toxic contaminant quinocide is now possible. As was shown by Schmidt et al. [45] and Baker et al. [46], and even repeated by Walker, Tekwani and Tripathi in their 2007 patent application, it is possible to achieve a three- to five-fold reduction in the pharmacologically active dose of monoenantiomeric primaquine versus to the primaquine used today.

\section{Materials and Methods}

\subsection{Sample Preparation}

Primaquine diphosphate of pro analysis (p.a.) quality (batch 16039; Sigma-Aldrich Chemie GmbH, Steinheim, Germany) and quality standard quinocide dihydrochloride (batch 17172) were used [11,12]. The following solutions were prepared in $10 \mathrm{~mL}$ of organic modifier, comprising EtOH (Arcus, Oslo, Norway) with $0.4 \%$ (v/v) diethylamine (Merck, Darmstadt, Germany): mixture 1 was $95 \%$ primaquine $/ 5 \%$ quinocide $(\mathrm{mol} / \mathrm{mol})$ and $\mathrm{mix}$ ture 2 was $95 \%$ quinocide $/ 5 \%$ primaquine $(\mathrm{mol} / \mathrm{mol})$.

\subsection{SFC-MS Instrumentation Used for High-Speed Separation of Quinocide from Primaquine and for Resolution of the Primaquine Enantiomers and Their Separation from Quinocide in One Run}

A MiniGram SFC (Berger Instruments Inc., USA) with SFC-ProNTo software (Berger Instruments Inc.) was equipped with a K-2501 UV detector (Advanced Scientific Instruments Dr. Ing. Herbert Knauer GmbH, Berlin, Germany). The MiniGram SFC was equipped with a fixed splitter that diverted part of the flow stream to feed the mass spectrometer in proportions 10/1 (UV/MS). The connecting line to the mass spectrometer was through $\mathrm{T}$-form tubing equipped with a manually operated microvalve and a capillary restrictor. The Micromass PLCZ 4190 mass spectrometer equipped with electrospray ionization (ESI) with MassLynx 4.0 software (Waters-Micromass, Manchester, UK) was used. The instrument had been previously calibrated with sodium iodide and operated in the positive charge mode.

\subsection{The Columns Used}

A Discovery ${ }^{\circledR}$ HS F5 column $(250 \mathrm{~mm}$ long with a 4.6 $\mathrm{mm}$ i. d. and $6 \mu \mathrm{m}$ particle size; Supelco, Bellefonte, PA, USA), a YMC-Pack C30 column (250 mm long with a $4.6 \mathrm{~mm}$ i. d. and $5 \mu \mathrm{m}$ particle size; YMC Co., Ltd., YMC Karasuma-Gojo, Kyoto, Japan) and an experimental HRIC column with high isomer resolution $(250 \mathrm{~mm}$ long with a $4.6 \mathrm{~mm}$ i. d. and $5 \mu \mathrm{m}$ particle size; Jupiter Ltd., Norway) were used.

\subsection{Mode of Operation of SFC-MS and Conditions of Detection}

Isocratic chromatography was performed using $\mathrm{CO}_{2}$ in the supercritical state with $20 \%$ organic modifier $(\mathrm{EtOH} /$ $0.4 \%$ diethylamine $(\mathrm{v} / \mathrm{v}))$ in experiments with a Discovery ${ }^{\circledR}$ HS F5 column and an YMC-Pack C30 column. Isocratic chromatography was performed using $\mathrm{CO}_{2}$ in the supercritical state with $15 \%$ organic modifier $(\mathrm{EtOH} /$ $0.4 \%$ diethylamine $(\mathrm{v} / \mathrm{v}))$ in experiments with an experimental HRIC column with high resolution of isomers. At the end of the analysis, the manually operated microvalve was closed, thus closing the flow of eluate to the mass spectrometer; the tubing directing the eluate to the waste flow restrictor was then opened. The percentage of modifier in the eluate was increased to $50 \%$ at a rate of $10 \%$ per min, and then held at $50 \%$ for $3 \mathrm{~min}$. It was then reduced to the level required for analysis at a rate of $10 \%$ per min, where it was held for $3 \mathrm{~min}$ to stabilize the column. The manually operated microvalve was then re- 
opened to direct the eluate to the mass spectrometer for 3 min before the start of the analysis.

UV detection was performed at a wavelength of 261 $\mathrm{nm}$. The MS conditions were a cone voltage of $60 \mathrm{~V}$, extractor voltage of $12 \mathrm{~V}$, capillary voltage of $4.5 \mathrm{kV}$, ion energy of $1.0 \mathrm{~V}$, multiplier at $400 \mathrm{~V}$, analyzer vacuum of $2.6 \mathrm{kPa}$ and a desolvation gas flow of $495 \mathrm{~L} \cdot \mathrm{h}^{-1}$. The mass-to-charge ratio was scanned automatically in the range of 80 to 400 . The presence of primaquine and quinocide in chromatograms were analytically detected by MS and compared with the mass spectra of MS spectra of these substances published in the literature $[16,17,19$ 23].

\section{Results and Discussion}

The separation of primaquine from quinocide in mixtures
1 and 2 on a Discovery ${ }^{\circledR}$ HS F5 column is shown in Figure 1 as red and blue lines, respectively. For a comparison of the effectiveness of separation of these substances, Figure 1 shows the high-speed separation of primaquine and quinocide in mixture 1 on an YMC-Pack C30 column (black line).

The resolution of enantiomers of primaquine and separation of quinocide from them in a single run on HRIC is shown in Figure 2.

It is obvious that the YMC-Pack C30 column has the same separation ability for these substances as a Discovery ${ }^{\circledR}$ HS F5 column; however, the time of analysis is much shorter on the YMC-Pack C30 column. This column has the advantage in analysis of primaquine in the unprocessed raw state and in tablets (medical form) because of the shorter time requirement. Neither Discovery ${ }^{\circledR}$ HS F5

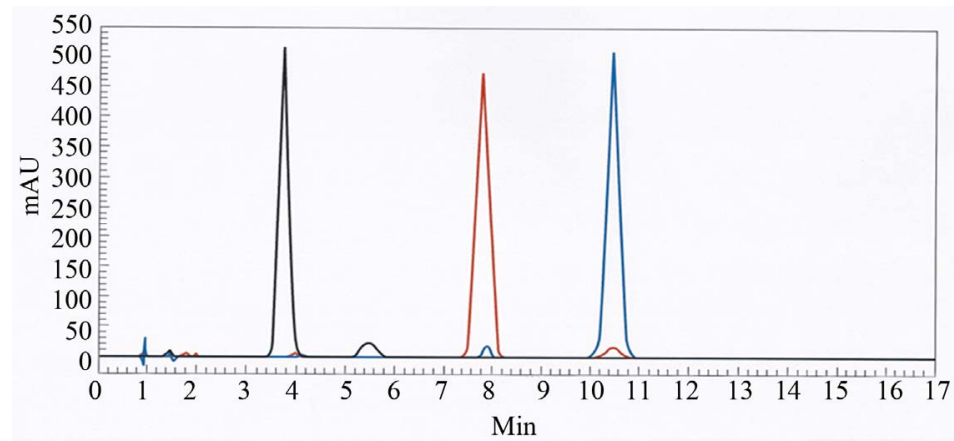

Figure 1. The red line (the major peak at $8 \mathrm{~min}$ is primaquine and the minor peak between 10 and 11 min is quinocide) shows the separation of primaquine from quinocide in mixtures 1 and the blue line (the minor peak at 8 min is primaquine and the major peak between 10 and $11 \mathrm{~min}$ is quinocide) shows the separation of primaquine from quinocide in mixtures 2 on a Dis$\operatorname{covery}^{\circledR}$ HS F5 column. The black line shows the high-speed separation of primaquine (major peak) and quinocide (minor peak) in mixture 1 on an YMC-Pack C30 column.

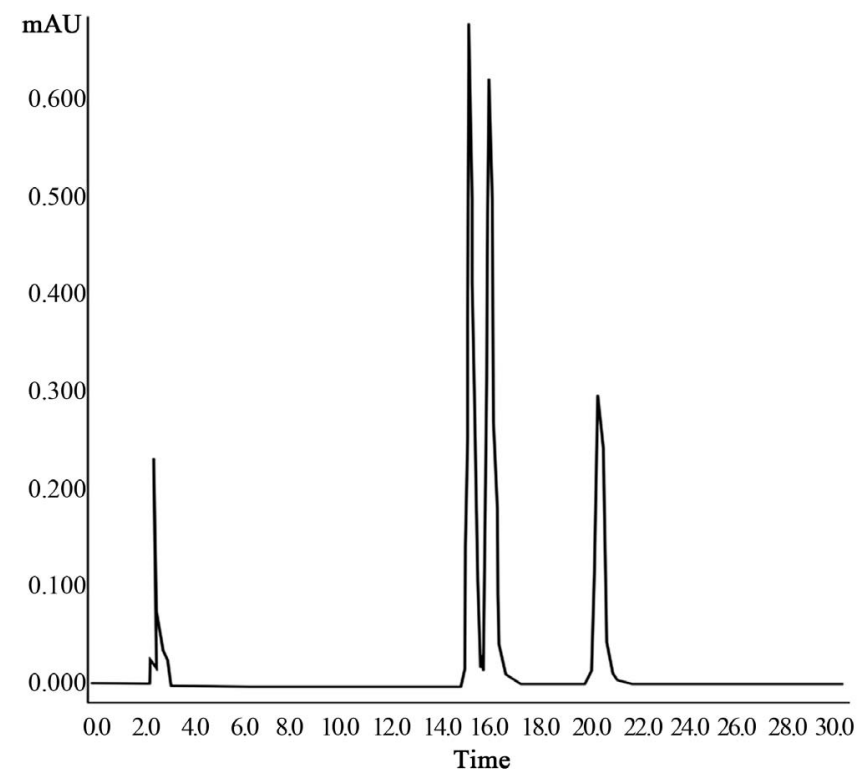

Figure 2. The resolution of the enantiomers of primaquine and their separation from quinocide is shown in one run. The major peaks between 14 and $18 \mathrm{~min}$ are enantiomers of primaquine; the peak at $20 \mathrm{~min}$ is quinocide. 
not YMC-Pack C30 column has the ability to resolve the enantiomers of primaquine.

The experimental HRIC column with high resolution of isomers is simultaneously resolved the enantiomers of primaquine and separated the quinocide (which is a substitutional isomer of primaquine) from these enantiomers, in one run (Figure 2). This column has a high ability to resolve enantiomers, with a simultaneous high ability to separate different isomers in mixtures.

This ability is important for the separation of all isomers in a mixture such as the drug primaquine. This ability is also important for other mixtures of enantiomers and isomers of drugs in the pharmaceutical industry, as well as for pesticides in pesticide-producing industries.

The productivity of the fractionation columns in SFC is very high, making possible the production of hundreds of kilograms of pure substances. The HRIC technology can be upgraded from analytical to semianalytical and even to industrial production scale.

The introduction discussed the advantages of the medical use of pure primaquine, free of contamination from quinocide, and given in the form of a monoenantiomeric substance that excludes the more toxic silent enantiomer. An attempt to produce the monoenantiomeric primaquine by reacting the primaquine mixture with chiral acid described by Walker, Tekwani and Tripathi (Patent Application Pub. No. US 2007/0190188 A1 of August 16, 2007) was criticized in [23], in part because the patent is not a pure one. It is compromised by earlier publications such as [45], which not only describes the phenomenon of different pharmacological activities of 8 -aminoquinolines but also gives the process of preparation of $l$ - and $d$ - enantiomers. In addition to this, analysis of the results of the preparation show clear contamination of the monoenantiomeric product with quinocide [23]. There is very little to gain from the process described in this patent because of contamination of the product with quinocide.

The research conducted and ongoing to prepare antimalarial vaccines are important, but it can take a decade or longer before a useful and safe vaccine is available for common use. Primaquine is a well-known substance, and its preparation using SFC equipped with a HRIC column with high resolution of isomers can be even less expensive than enantiospecific synthesis, since the latter would still have to be followed by a purification step to remove quinocide contamination.

Other new and promising antimalarial drugs are needed; one of them is tafenoquine. Tafenoquine in many ways resembles primaquine. Analysis of a sample of tafenoquine received from GSK on the HRIC column was even more intriguing than that of primaquine; however, discussion of the results is beyond the scope of this paper. Readers who are interested in this subject are directed to publication [23].

\section{Conclusions}

1) Pharmacopoeia committees are incorrect to ignore the contamination of primaquine with quinocide; it is unproductive and even in contradiction to these committees' duty of care, from a legal point of view.

2) The analytical procedures for measuring quinocide in primaquine, both qualitatively and quantitatively, are described in the literature.

3) Monoenantiomeric primaquine is needed and can be prepared at reasonable cost using SFC equipped with a HRIC column with high isomer resolution.

4) It is time for pharmacopoeia committees to recognize that the presence of toxic contamination at a level of $1.5 \%$ in the drug primaquine phosphate is no longer tolerable.

\section{Acknowledgements}

The authors are grateful to engineer Jon Reierstad at the Technical Department, Photo and Graphic Laboratory, University of Oslo, Norway for technical support and to Jupiter Ltd., Norway for standards, experimental high resolution isomers column HRIC and financial support.

\section{REFERENCES}

[1] J. W. Tracy, L. T. Webster, "Drugs Used in the Chemotherapy of Protozoal Infections," In: J. G. Hardman and L. E. Limbird, Eds., The Pharmacological Basis of Therapeutics, 9th Edition, McGraw-Hill Book Co., New York, 1996, pp. 987-1008.

[2] I. Brondz, D. Mantzeilas, U. Klein, M. N. Lebedeva, F. S. Mikhailitsyn, G. D. Souleimanov and D. Ekeberg, "The Main Contaminant of the Antimalarial Drug Primaquine Is Its Positional Isomer," The 3rd International Symposium on Separation in BioSciences SBS 2003, A 100 Years of Chromatography, Moscow, 13-18 May 2003, p. 165.

[3] British Pharmacopoeia, Her Majesty's Stationery Office (HMSO), London, Vol. 1, 1988, p. 462.

[4] British Pharmacopoeia, Her Majesty's Stationery Office (HMSO), London, 1990, p. 1252 (Addendum).

[5] British Pharmacopoeia, Her Majesty's Stationery Office (HMSO), London, Vol. 1, 1993, p. 541.

[6] British Pharmacopoeia, Her Majesty's Stationery Office (HMSO), London, 1997, p. 2015 (Addendum).

[7] British Pharmacopoeia, Her Majesty's Stationery Office (HMSO), London, Vol. 1, 2000, p. 1285.

[8] European Pharmacopoeia, 3rd Edition, Council of Europe, Strasbourg, 1997.

[9] European Pharmacopoeia, 3rd Edition, Council of Europe, Strasbourg, 2001.

[10] I. Brondz, D. Mantzilas, U. Klein, D. Ekeberg, E. Hvattum, M. N. Lebedeva, F. S. Mikhailitsyn, G. D. Soulei- 
manov and J. Røe, "Nature of the Main Contaminant in the Antimalarial Drug Primaquine Diphosphate: A Qualitative Isomer Analysis," Journal of Chromatography B, Vol. 800, No. 1-2, 2004, pp. 211-223.

doi:10.1016/i.jchromb.2003.09.042

[11] I. Brondz, U. Klein, D. Ekeberg, D. Mantzilas, E. Hvattum, H. Schultz and F. S. Mikhailitsyn, "Nature of the Main Contaminant in the Anti-Malaria Drug Primaquine Diphosphate: GC-MS Analysis," International Symposium Analytical Forum, Warsaw, 4-8 July, 2004, p. 154.

[12] I. Brondz, U. Klein, D. Ekeberg, D. Mantzilas, E. Hvattum, H. Schultz and F. S. Mikhailitsyn, "Nature of the Main Contaminant in the Drug Primaquine Diphosphate: GC-MS Analysis," Asian Journal of Chemistry, Vol. 17, No. 3, 2005, pp. 1678-1688.

[13] I. Brondz and U. Klein, "Separation of the Positional Isomer Quinocide from the Antimalarial Drug Primaquine Using a Discovery ${ }^{\circledR}$ HS-F5 HPLC Column," The Reporter, Vol. 23, No. 4, 2005, p. 1.

[14] I. Brondz, D. Ekeberg, L. Karaliova, I. Jennings, J. A. Hustad and R. Svendsen, "Separation of the Positional Isomer Quinocide from the Anti-Malaria Drug Primaquine Using a Discovery HS-F5 HPLC Column," Trends in Chromatography, Vol. 1, 2005, pp. 78-81.

[15] I. Brondz and U. Klein, "Separation of the Positional Isomer Quinocide from the Anti-Malarial Drug Primaquine Using a Discovery ${ }^{\circledR}$ HS-F5 HPLC Column," The Reporter EU, Vol. 19, 2006, p. 3.

[16] I. Brondz, D. Ekeberg, D. S. Bell, J. A. Hustad, R. Svendsen, V. Vlachos, P. Oakley, G. J. Langley, T. Mohini, C.-G. Amaury and F. Mikhalitsyn, "Nature of the Main Contaminant in the Drug Primaquine Diphosphate: SFC and SFC-MS Methods of Analysis," Journal of Pharmaceutical and Biomedical Analysis, Vol. 43, No. 3, 2007, pp. 937-944. doi:10.1016/j.jpba.2006.09.017

[17] I. Brondz, D. Ekeberg, A. R. Annino and T. Palcic, "SFCMS Analyses of Anti-Malaria Drug Primaquine Diphosphate. Comparison of Techniques and Instrumentation," The 12th Norwegian MS Winter Meeting, Hafjell, 21-24 January 2007, p. 42.

[18] I. Brondz, A. B. Fialkov and A. Amirav, "Analysis of Quinocide in Unprocessed Primaquine Diphosphate and Primaquine Diphosphate Tablets Using Gas Chromatography-Mass Spectrometry with Supersonic Molecular Beams," Journal of Chromatography A, Vol. 1216, No. 5, 2009, pp. 824-829. doi:10.1016/j.chroma.2008.11.043

[19] I. Brondz, "SFC-MS Analysis of Contaminants in Primaquine Diphosphate Tablets and Spectral UV and NMR Characterizing of Primaquine and Quinocide," In: E. Csizmadia and I. Kalnoky, Eds., Antimalarial Drugs: Costs, Safety and Efficacy, Nova Science Publishers, Inc., New York, 2009, pp. 105-124.

[20] I. Brondz, "Improved Separation of Quinocide in Primaquine Analysis by Supercritical Fluid ChromatographyMass Spectrometry," The 5th Conference Nordic Separation Science Society, Tallinn, 26-29 August 2009, p. 6.

[21] I. Brondz, "SFC-MS Analysis of Contaminants in Primaquine Diphosphate Tablets and Spectral UV and NMR Characterizing of Primaquine and Quinocide," The 5th
Conference Nordic Separation Science Society, Tallinn, 26-29 August 2009, p. 7.

[22] I. Brondz, "Historical Overview of Chromatography and Related Techniques in Analysis of Anti-Malarial Drug Primaquine," In: T. J. Quintin, Ed., Chromatography: Types, Techniques and Methods, Nova Science Publishers, Inc., New York, 2010, pp. 281-322.

[23] I. Brondz, "Historical Overview of Chromatography and Related Techniques in Analysis of Antimalarial Drug Primaquine," Nova Science Publishers, Inc., New York, 2011.

[24] A. A. Elbashir, B. Saad, A. S. M. Ali, M. I. Saleh and H. Y. Aboul-Enein, "Enantioselective Analysis of Primaquine and Its Impurity Quinocide by Capillary Electrophoresis," Biomedical Chromatography, Vol. 23, No. 3, 2008 pp. 295-301. doi:10.1002/bmc.1113

[25] D. D. Sin and S. D. Shafran," Dapsone and PrimaquineInduced Methemoglobinemia in HIV-Infected Individuals," Journal of Acquired Immune Deficiency Syndromes, Vol. 12, No. 5, 1996, pp. 477-481. doi:10.1097/00042560-199608150-00006

[26] M. D. Coleman and N. A. Coleman, "Drug-Induced Methemoglobinemia-Treatment Issues," Drug Safety, Vol. 14, No. 6, 1996, pp. 394-405. doi:10.2165/00002018-199614060-00005

[27] T. C. Marrs, J. E. Bright and B. C. Morris, "Methemoglobinogenic Potential of Primaquine and Its Mutagenicity in the Ames Test," Toxicology Letters, Vol. 36, No. 3, 1987, pp. 281-287. doi:10.1016/0378-4274(87)90197-4

[28] G. S. Kantor, "Primaquine-Induced Methemoglobinemia During Treatment of Pneumocytis-Carinii Pneumonia," New England Journal of Medicine, Vol. 327, No. 20, 1992, pp. 1491-1462.

[29] R. Allahyari, A. Strother, I. M. Fraser and A. J. Verbiscar, "Synthesis of Certain Hydroxy Analogues of the Antimalarial Drug Primaquine and Their in vitro Methemoglobin-Producing and Glutathione-Depleting Activity in $\mathrm{Hu}-$ man Erythrocytes," Journal of Medicinal Chemistry, Vol. 27, No. 3, 1984, pp. 407-410.

[30] R. I. Wed, "Effects of Primaquine on the Red Blood Cell Membrane. II. $\mathrm{K}^{+}$Permeability in Glucose-6-Phosphate Dehydrogenase Deficient Erythrocytes," Journal of Clinical Investigation, Vol. 40, No. 1, 1961, pp. 140-143. doi:10.1172/JCI104227

[31] R. W. Kellermeyer, P. E. Carson, S. L. Schrier, A. R. Tarlov and A. S. Alving, "The Hemolytic Effect of Primaquine. XIV. Pentose Metabolism in Primaquine-Sensitive Erythrocytes," Journal of Laboratory and Clinical Medicine, Vol. 58, 1961, pp. 715-724.

[32] R. J. Dern, E. Beutler and A. S. Alving, "The Hemolytic Effect of Primaquine V. Primaquine Sensitivity as a Manifestation of a Multiple Drug Sensitivity," Journal of Laboratory and Clinical Medicine, Vol. 97, No. 6, 1981, pp. 750-759.

[33] I. G. Schmidt and L. H. Schmidt, "Neurotoxicity of the 8-Aminoquinolines. I. Lesions in the Central Nervous System of the Rhesus Monkey Induced by Administration of Plasmocid," Journal of Neuropathology \& Experimental Neurology, Vol. 7, No. 4, 1948, pp. 368-398. doi:10.1097/00005072-194810000-00002 
[34] I. G. Schmidt and L. H. Schmidt, "Neurotoxicity of the 8-Aminoquinolines. II. Reactions of Various Experimental Animals to Plasmocid," Journal of Neuropathology \& Experimental Neurology, Vol. 91, No. 3, 1948, pp. 337367.

[35] D. Bullimore, "The Role of Polyamines in Hepatic Encephalopathy and Cerebral Oedema," European Journal of Gastroenterology \& Hepatology, Vol. 5, No. 2, 1993, pp. 63-67.

[36] A. M. Rønn, J. Rønne-Rasmussen, P. C. Gøtzsche, I. C. Bygbjerg, "Neuropsychiatric Manifestations after Mefloquine Therapy for Plasmodium Falciparum Malaria: Comparing a Retrospective and a Prospective Study," Tropical Medicine and International Health, Vol. 3, No. 2, 1998, pp. 83-88. doi:10.1046/j.1365-3156.1998.00163.x

[37] M. M. El-Mofty, V. V. Khudoley, S. A. Skar and H. S. Abdelgawad, "The Carcinogenicity of Some Antimalarial Drugs Using the Egyptian Toad Bufo Regularis as a Biological Test Animal," Nutrition and Cancer, Vol. 18, No. 2, 1992, pp. 191-198. doi:10.1080/01635589209514219

[38] S. G. Orta, R. A. Bouchard, S. F. Morales and E. M. Salinas-Stefanon, "Inhibition of Cardiac $\mathrm{Na}^{+}$Current by Primaquine," British Journal of Pharmacology, Vol. 135, No. 3, 2002, pp. 751-753. doi:10.1038/sj.bjp.0704460

[39] J .W. Tracy and L. T. Webster, "Drugs Used in the Chemotherapy of Protozoal Infections: Malaria," In: J. G. Hardman, L. E. Limbird, A. G. Gilman, Goodman and Gilman, Eds., The Pharmacological Basis of Therapeutics, 10th Edition, McGraw-Hill, Book Co., New York, 2001, pp. 1069-1095.

[40] R. Ash-Bernal, R. Wise and S. M. Wright, "Acquired Methemoglobinemia: A Retrospective Series of 138 Case at 2 Teaching Hospitals," Medicine (Baltimore), Vol. 83, No. 5, pp. 265-273.

[41] M. N. Lebedeva and V. M. Brusilovskaia, "Acute Toxic Action of Combinations of a New Antimalarial Preparation, Dabequine," Meditsinskaia Parazitologiia i Parazitarnye Bolezni, Vol. 49 No. 6, 1980, pp. 27-31.

[42] P. H. Schlesinger, D. J. Krogstad and B. L. Herwaldt, "Antimalarial Agents: Mechanisms of Action," Antimicrobial Agents and Chemotherapy, Vol. 32, No. 6, 1988, pp. 793-
798. doi:10.1128/AAC.32.6.793

[43] J. G. Olenick and F. E. Hahn, "Mode of Action of Primaquine: Preferential Inhibition of Protein Biosynthesis in Bacillus megaterium," Antimicrobial Agents and Chemotherapy, Vol. 1, No. 3, 1972, pp. 259-262. doi:10.1128/AAC.1.3.259

[44] J. K. Baker, R. H. Yarber, N. P. D. Nanayakkara, J. D. McChesney, F. Homo and I. Landau, "Effects of Aliphatic Side-Chain Substituents on the Antimalarial Activity and on the Metabolism of Primaquine Studied Using Mitochondria and Microsome Preparations," Pharmaceutical Research, Vol. 7, No. 1, 1990, pp. 91-95. doi:10.1023/A:1015899928897

[45] L. H. Schmidt, S. Alexander, L. Allen and J. Rasco, "Comparison of the Curative Antimalarial Activities and Toxicities of Primaquine and Its $d$ and $l$ Isomers," Antimicrobial Agents Chemotherapy, Vol. 12, No. 1, 1977, pp. 5160. doi:10.1128/AAC.12.1.51

[46] J. K. Baker and J. D. McChesney, "Differential Metabolism of the Enantiomers of Primaquine," Journal of Pharmaceutical Sciences, Vol. 77, No. 5, 1988, pp. 380-382. doi:10.1002/jps.2600770503

[47] A. Brossi, P. Millet, I. Landau, M. E. Bembenek and C. W. Abell, "Antimalarial Activity and Inhibition of Monoamine Oxidases A and B by Exo-Erythrocytic Antimalarials. Optical Isomers of Primaquine, N-Acylated Congeners, Primaquine Metabolites and 5-Phenoxy-Substituted Analogues," FEBS Letters, Vol. 214, No. 2, 1987, pp. 291-294.

[48] D. R. Brocks and R. Mehvar, "Stereoselectivity in the Pharmacodynamics and Pharmacokinetics of the Chiral Antimalarial Drugs," Clinical Pharmacokinetics, Vol. 42, No. 15, 2003, pp. 1359-1382. doi:10.2165/00003088-200342150-00004

[49] F. I. Carroll, B. Berrang and C. P. Linn, "Resolution of Antimalarial Agents via Complex Formation with $\alpha-(2,4$, 5,7-Tetranitro-9-Fluorenylideneaminooxy) Propionic Acid," Journal of Medical Chemistry, Vol. 21, No. 4, 1978, pp. 326-330. doi:10.1021/jm00202a002 